This item was submitted to Loughborough's Research Repository by the author.

Items in Figshare are protected by copyright, with all rights reserved, unless otherwise indicated.

\title{
Determination of subject-specific model parameters for visco-elastic
} elements

PLEASE CITE THE PUBLISHED VERSION

PUBLISHER

(C) Elsevier

VERSION

AM (Accepted Manuscript)

LICENCE

CC BY-NC-ND 4.0

\section{REPOSITORY RECORD}

Wilson, Cassie, Mark A. King, and Maurice R. Yeadon. 2019. "Determination of Subject-specific Model Parameters for Visco-elastic Elements". figshare. https://hdl.handle.net/2134/6186. 
This item was submitted to Loughborough's Institutional Repository (https://dspace.lboro.ac.uk/) by the author and is made available under the following Creative Commons Licence conditions.

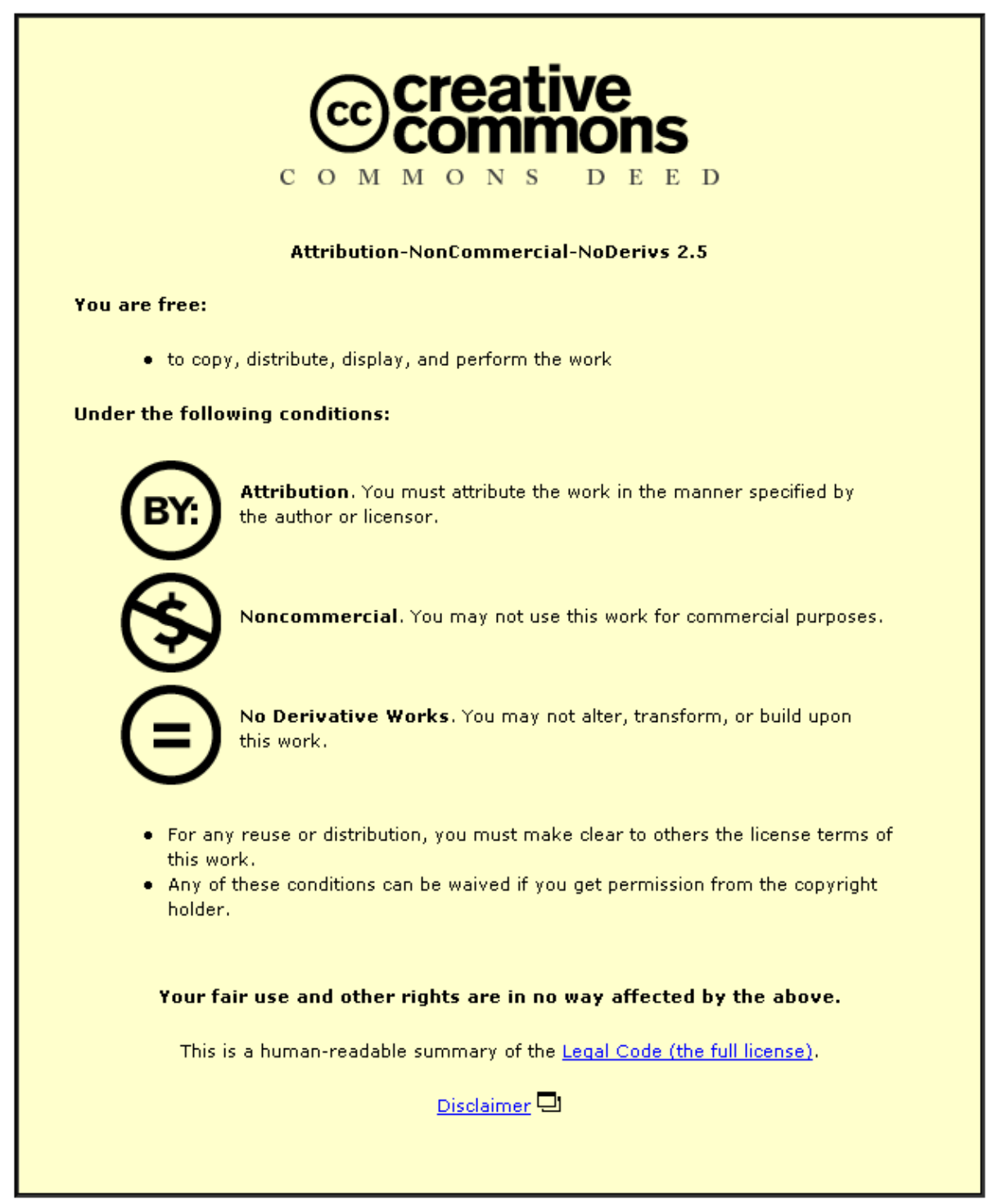

For the full text of this licence, please go to: http://creativecommons.org/licenses/by-nc-nd/2.5/ 


\title{
Determination of subject-specific model parameters for visco-elastic elements
}

\author{
Cassie Wilson $^{1}$, Mark A. King ${ }^{2}$ and Maurice R. Yeadon ${ }^{2}$ \\ ${ }^{1}$ School of Sport, PE and Recreation. University of Wales Institute Cardiff, Cardiff, CF23 6XD, UK. \\ ${ }^{2}$ School of Sport and Exercise Sciences, Loughborough University, Loughborough LE11 3TU, UK.
}

\begin{abstract}
The determination of subject-specific model parameter values is necessary in order for a computer simulation model of human motion to be evaluated quantitatively. This study used an optimisation procedure along with a kinematically-driven simulation model of the contact phase in running jumps to determine the elastic parameters of segmental wobbling masses and the foot-ground interface. Kinetic and kinematic data were obtained on a running jump for height and a running jump for distance performed by an elite male high jumper. Stiffness and damping coefficients of the visco-elastic elements in the model were varied until the difference between simulation and performance was minimised. Percentage differences of $6 \%$ and $9 \%$ between the simulated and recorded performances were obtained in the jumps for height and distance respectively. When the parameters obtained from the jump for height were used in a simulation of the jump for distance (and vice versa) there was poor agreement with the recorded jump. On the other hand a common set of visco-elastic parameters were obtained using the data from both recorded jumps resulting in a mean difference of only $8 \%$ (made up of $7 \%$ and $10 \%$ ) between simulation and performance that was almost as good as the individual matches. Simulations were not overly sensitive to perturbations of the common set of visco-elastic parameters. It is concluded that subject-specific elastic parameters should be calculated from more than a single jump in order to provide a robust set of values that can be used in different simulations.
\end{abstract}

Keywords: computer simulation model, parameters, subject-specific

\section{Introduction}

Computer simulation models are often used to investigate the biomechanics of sports movements (Hatze, 1981; Hubbard et al., 1989, Neptune and Hull, 1999; van Soest et al., 1993). Advantages of simulation studies over experimental studies include the control of variables, the consideration of hypothetical situations, and the optimisation of performance (Yeadon and Challis, 1994). Simulation models require realistic input data as well as realistic model parameter values and these may be obtained from data on actual performances and from measurements made on a subject. It is a major advantage to be able to customise a simulation model to an individual by using subject-specific parameter values as this allows the model to be evaluated quantitatively by comparing the simulation output with the individual's own performance (King and Yeadon, 2002). In general, there is little quantitative evaluation of biomechanical models and this is a weakness of the field.

Model parameters can be divided into three major categories: strength, inertia, and elastic parameters. Determination of subject-specific strength parameters has been achieved using isovelocity dynamometer measurements (King and Yeadon, 2002). Various methods have been used to determine personalised inertia parameters including geometric models of body segments (Hatze, 1980, Jensen, 1978, Yeadon, 1990b). During an impact such as heel strike in running the skeletal structures of the body experience high accelerations whereas the soft tissue acceleration is delayed (Nigg et al., 1995). As a consequence the approximation of the human body as a system of linked rigid segments is only justifiable for movements that are not too rapid (Denoth et al., 1985). Wobbling mass models have been developed where each segment is represented by a combination of both a fixed and a wobbling part (Gruber et al., 1998). The foot-ground interface can also be represented using a force-deformation 
model, and the simulation results may be compared to experimental force measurements (van den Bogert and Nigg, 1999).

Determining these visco-elastic parameters experimentally is a challenge, but one which can be surmounted (Pain and Challis, 2001). An alternative approach is to estimate the parameter values using a computer simulation model by minimising the difference between simulated and actual performances. This has been done for tumbling using a torque-driven model (Yeadon and King, 2002) and for running using a muscle-driven model (Neptune et al., 2000). In such an approach the number of parameters to be determined should be minimal and the simulation model should have only a few degrees of freedom. It may be argued that this can be better achieved using a kinematically-driven model rather than a kinetically-driven model since the technique is already specified and therefore there are fewer performance parameters that can vary.

The purpose of this study was to determine subject-specific visco-elastic parameters using a kinematically-driven simulation model of the contact phase in running jumps and to determine the sensitivity of model performance to these parameter values in different jumping activities. The intention is that these parameters may be used subsequently in a torque-driven model in order to investigate optimum jumping technique.

\section{Method}

A computer simulation model of the contact phase in running jumps was developed and was customised to an elite male high jumper through the determination of subject-specific parameters. The visco-elastic parameters were determined by comparing simulations with actual performances of running jumps by the athlete and varying the parameter values until the best match was achieved.

An international male high jumper of height $1.89 \mathrm{~m}$ and mass $82 \mathrm{~kg}$, with a personal best competition performance of $2.31 \mathrm{~m}$ was used as the subject in the study. The athlete gave informed consent for the procedures, which were carried out in accordance with the protocol approved by Loughborough University Ethical Advisory Committee. Ninety-five anthropometric measurements were taken on the subject and segmental inertia parameters were calculated using the geometric inertia model of Yeadon (1990b). Trials of a running jump for height and a running jump for distance were recorded in a laboratory setting. Force data were collected during the contact phase of each trial using a Kistler force plate sampled at $800 \mathrm{~Hz}$. The duration of contact of each trial was determined using the force data and was therefore considered to be accurate to within $2.5 \mathrm{~ms}$. Two $50 \mathrm{~Hz}$ Sony digital Handycam VX1000 cameras and a NAC high speed HSV-400 video camera operating at $200 \mathrm{~Hz}$ were used to obtain kinematic data from each trial. Fifteen body landmarks (wrist, elbow, shoulder, hip, knee, ankle and toe on each side of the body plus the centre of the head) were digitised in each field of the movement sequence from each of the three camera views. The two $50 \mathrm{~Hz}$ cameras (one at the side and one behind) recorded the approach, contact, and flight phases of the trials whilst the $200 \mathrm{~Hz}$ camera (placed at the side) viewed a volume encompassing the contact phase. Using a common $50 \mathrm{~Hz}$ camera (behind the approach), two camera pairings were established and 11 Direct Linear Transform (DLT) parameters and a central lens distortion parameter were calculated for each camera (Karara, 1980). The method of Yeadon and King (1999) was used with interpolating splines to synchronise the video data and the 3D locations of each digitised point were reconstructed using the method of Karara (1980). The use of a $50 \mathrm{~Hz}$ camera in the $200 \mathrm{~Hz}$ reconstruction of the contact phase was not a severe limitation since the lateral movement information that it provided had small amplitude and low frequency. 3D image analysis with two cameras was used in preference to $2 \mathrm{D}$ analysis since spatial reconstruction using a single camera is subject to errors arising from body landmarks not lying in the calibrated plane and this can result in substantial errors in 
mass centre velocity. The coordinate data and the inertia data were then used to calculate the mass centre displacement and the orientation and configuration angles throughout each movement (Yeadon, 1990a) and these were fitted using quintic splines (Wood and Jennings, 1979 ) in order to calculate velocity estimates and the angular momentum about the mass centre (Yeadon, 1990c).

A planar eight-segment angle-driven forward dynamics model consisting of a foot, calf, and thigh of the takeoff leg, shank and thigh of the free leg, and a trunk, upper arm, and lower arm (representing both arms) was developed to model the foot contact phase from touchdown to takeoff in running jumps for height and distance (Figure 1).

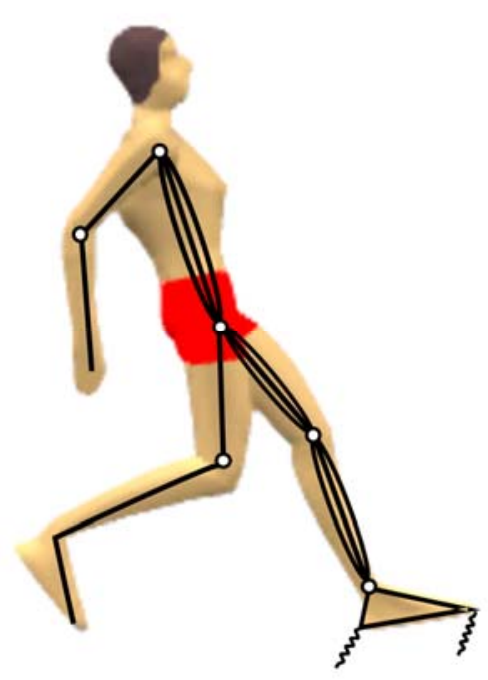

Figure 1. Eight segment simulation model of the takeoff in jumping. Wobbling masses are situated within the shank and thigh of the takeoff leg and trunk segments, and visco-elastic springs are situated at the heel and toe representing the foot-ground interface

Movement of the soft tissue in the takeoff leg and trunk was modelled using (rigid) wobbling masses connected by visco-elastic elements to fixed linked masses representing the bones of the shank, thigh and trunk segments. The inertia parameters for the fixed and wobbling masses were calculated using ratios of wobbling mass to fixed mass based on data from Clarys and Marfell-Jones (1986). The fixed mass in a segment was modelled as a uniform cylinder of known length with a density value of 1.1 (Dempster, 1955). The inertia parameters for the wobbling mass were then determined in such a way that the combined mass centre position and moment of inertia were equal to those calculated previously for the whole segment using the inertia model of Yeadon (1990b).

Spring-dampers with vertical and horizontal components (equations (1) and (2)), situated at each end of a segment were used to attach the wobbling mass to the corresponding fixed mass.

$$
\begin{aligned}
& \mathrm{F}_{\mathrm{x}}=(-\mathrm{kx}-\mathrm{b} \dot{\mathrm{x}})|\mathrm{x}| \\
& \mathrm{F}_{\mathrm{y}}=(-\mathrm{ky}-\mathrm{by})|\mathrm{y}|
\end{aligned}
$$

where $\mathrm{x}$ is the horizontal displacement of the spring, $\mathrm{y}$ is the vertical displacement of the spring, $\mathrm{k}$ is the horizontal and vertical stiffness, $\mathrm{b}$ is the horizontal and vertical damping.

The foot-ground interface was modelled in a similar way using damped springs with horizontal and vertical elements situated between the ground and the heel, and the ground and the toe. The vertical and horizontal ground reaction forces at the toe were determined using 
equations (3) and (4). Equations of the same form were used for the determination of the forces at the heel.

$$
\begin{gathered}
\mathrm{F}_{\mathrm{yt}}=\left(-\mathrm{k}_{\mathrm{yt}} \mathrm{y}_{\mathrm{t}}-\mathrm{b}_{\mathrm{yt}} \dot{\mathrm{y}}_{\mathrm{t}}\right)\left|\mathrm{y}_{\mathrm{t}}\right| \\
\mathrm{F}_{\mathrm{xt}}=\left[\mathrm{F}_{\mathrm{yt}} /\left(\mathrm{F}_{\mathrm{yt}}+\mathrm{F}_{\mathrm{yh}}\right)\right]\left[-\mathrm{k}_{\mathrm{xt}} \mathrm{x}|\mathrm{x}|-\mathrm{b}_{\mathrm{xt}} \dot{\mathrm{x}}|\mathrm{x}| /\left(1+\mathrm{c}_{\mathrm{xt}}|\mathrm{x}|\right)\right] \mathrm{y}_{\mathrm{t}}^{2}
\end{gathered}
$$

where $\mathrm{k}_{\mathrm{x}}, \mathrm{k}_{\mathrm{y}}$ and $\mathrm{b}_{\mathrm{x}}, \mathrm{b}_{\mathrm{y}}$ are the horizontal and vertical stiffness and damping constants, $\mathrm{c}_{\mathrm{x}}$ is a constant, $\mathrm{x}$ is the horizontal depression of the spring, $\mathrm{y}$ is the vertical depression of the spring and subscripts $t$ and $h$ refer to toe and heel respectively. The first term on the RHS of equation (4) was used to ensure that there were horizontal forces at the heel or toe only when there were vertical forces there. The effect of the $c_{x}$ term was to limit the influence of $x$ on the damping for large horizontal displacements. The whole expression was multiplied by $\mathrm{y}^{2}$ to reflect the fact that greater forces are required for a given horizontal displacement when the vertical depression is greater.

There were 12 degrees of freedom in the model: nine variables defining wobbling mass movement, two variables defining mass centre position and one variable defining body orientation. The model was implemented using the software package Autolev ${ }^{\mathrm{TM}_{3}}$ which is based on Kane's method of formulating the equations of motion (Kane and Levinson, 1996). Input to the model comprised mass centre location and velocity at touchdown, trunk orientation and angular velocity at touchdown, and joint angles and angular velocities throughout the simulation. The output from the model comprised time histories of foot and wobbling mass displacements and whole body orientation during contact from which whole body angular momentum and mass centre velocity at takeoff were obtained.

In order to determine the visco-elastic parameters for both the foot-ground interface and the wobbling masses, the Simulated Annealing optimisation algorithm (Corana et al., 1987) was used to minimise the difference between simulated and recorded performances. In total 30 parameters were varied in the optimisation procedure. There were seven (rather than 10) foot-ground interface parameters, the horizontal stiffness and damping constants at the heel and toe being set equal as were the $c_{x}$ terms (equations (3) and (4)) in order to reduce the number of parameters. There were six (rather than 12) wobbling mass visco-elastic parameters, the horizontal and vertical stiffness and damping constants being set equal (equations (1) and (2)) in order to reduce the number of parameters. The visco-elastic parameter values were allowed to vary by $\pm 50 \%$ from initial estimates obtained from Gilchrist and Winter (1996) for the foot-ground interface parameters, and from trial simulations for the wobbling mass parameters. In addition there were 17 kinematic parameters which allowed small variations in the initial whole body orientation and angular velocity and the joint angle time histories of the ankle, knee and hip of the takeoff leg in order to compensate for errors in the digitised data. The initial whole body orientation and angular velocity were allowed to vary by $\pm 1^{\circ}$ and $\pm 50^{\circ} \mathrm{s}^{-1}$ from the initial conditions estimated from the video analysis (Yeadon and King, 2002) and the joint angle time histories for the ankle, knee and hip of the takeoff leg were varied by up to $3^{\circ}$ during a simulation. This was achieved by adding five terms of a Fourier sine series $\left(1 \mathrm{~Hz}-5 \mathrm{~Hz}\right.$, with coefficients up to $\left.1^{\circ}\right)$ to the time history of each joint angle. Each simulation was given a score comprising six components to assess how well the simulated and recorded performances matched. Component (1) was calculated as the absolute difference in the body orientation at takeoff (measured in degrees); component (2) was calculated as the RMS difference in the joint angles at takeoff (measured in degrees); component (3) was calculated as the percentage absolute difference in the time of contact; component (4) was calculated as the percentage RMS difference in the horizontal and vertical linear momentum at takeoff; component (5) was calculated as the percentage absolute difference in the angular momentum at takeoff; component (6) was calculated as the overall RMS difference in the time histories of the horizontal and vertical ground reaction forces 
during the takeoff phase as a percentage of peak force. The whole body angular momentum at takeoff was small so the weighting of component (5) was adjusted so that a $1 \%$ error in the angular momentum at takeoff was equivalent to $1^{\circ}$ error in rotation on landing after the flight phase. The overall RMS difference expressed as a percentage was then calculated from the six components with all components equally weighted since differences in degrees and percentages were considered to give comparable measures (Yeadon and King, 2002). In order to ensure realistic movements of the wobbling masses relative to the fixed masses and realistic depressions of the foot-ground interface, penalties were added to the score for a simulation if unrealistic movement of the visco-elastic springs occurred. No penalties were incurred in the final optimum solutions. This optimisation procedure was used for the jumps for height and distance. To ensure that the Simulated Annealing algorithm found the global optimum, additional optimisations were run with different initial parameter estimates and with the parameters in a different order. The additional optimisations produced no improvement in the global optimum.

The jumps for height and distance produced two sets of stiffness and damping parameter values for the wobbling masses and the foot-ground interface. As the two jumps had been performed on the same surface by the same subject it was expected that the wobbling mass and foot-ground interface visco-elastic parameters should be the same. A common set of parameters was therefore determined by minimising the mean score for the two jumps. In order to assess the overall sensitivity of the model to the visco-elastic parameters, the parameters determined for the jump for height were used in the simulation of the jump for distance and vice versa. To assess the sensitivity to each individual parameter, simulation scores were obtained with each parameter individually changed by $10 \%$ from the common set value. In addition the peak forces corresponding to each stiffness and damping parameter were calculated using equations (1) - (4) in order to compare their relative contributions and were expressed as a percentage of the overall peak force reached during takeoff for that elastic element. To assess the effect of including the additional 17 kinematic parameters which allowed for errors in the digitised data, the variation allowed for by each additional parameter was removed in turn using single simulations. A combined optimisation was also carried out without the additional 17 kinematic parameters.

Takeoff characteristics comprising linear and angular momenta and body orientation, obtained as output from the simulation model, and joint angle configuration time histories, obtained from the video data, were used as input to an angle-driven simulation model of aerial movement (Yeadon et al., 1990) to determine the resulting motion in the flight phase.

\section{Results}

Personalised inertia parameter values for the fixed and wobbling masses were obtained (Table 1). Three sets of subject-specific visco-elastic parameters were determined: two for the individual trials and one for the combination of the two trials (Table 2). 
Table 1. Segmental inertia values for the fixed and wobbling masses

\begin{tabular}{|c|c|c|c|c|c|}
\hline segment & part & $\begin{array}{c}\text { mass } \\
{[\mathrm{kg}]}\end{array}$ & $\begin{array}{l}\text { length } \\
\text { [m] }\end{array}$ & $\begin{array}{l}\mathrm{CM} \\
{[\mathrm{m}]}\end{array}$ & $\begin{array}{c}\text { MoI } \\
{\left[\mathrm{kg} \cdot \mathrm{m}^{2}\right]}\end{array}$ \\
\hline \multirow{2}{*}{$\begin{array}{c}\text { trunk + } \\
\text { head }\end{array}$} & fixed & 4.052 & \multirow[t]{2}{*}{0.898} & 0.449 & 0.275 \\
\hline & wob & 34.896 & & 0.361 & 1.694 \\
\hline \multirow[t]{2}{*}{ left thigh } & fixed & 2.638 & \multirow[t]{2}{*}{0.429} & 0.215 & 0.043 \\
\hline & wob & 8.232 & & 0.170 & 0.125 \\
\hline \multirow[t]{2}{*}{ left shank } & fixed & 1.554 & \multirow[t]{2}{*}{0.459} & 0.230 & 0.028 \\
\hline & wob & 3.223 & & 0.172 & 0.044 \\
\hline upper arms & fixed & 5.322 & 0.137 & 0.317 & 0.050 \\
\hline lower arms & fixed & 3.804 & 0.166 & 0.481 & 0.055 \\
\hline right thigh & fixed & 10.588 & 0.184 & 0.435 & 0.176 \\
\hline $\begin{array}{l}\text { right calf } \\
\text { and foot }\end{array}$ & fixed & 6.115 & 0.247 & 0.450 & 0.161 \\
\hline left foot & fixed & 1.478 & 0.090 & 0.243 & 0.006 \\
\hline
\end{tabular}

Note: wob - wobbling mass, CM distance from proximal joint, moments of inertia (MoI) about transverse axis through the mass centre of each mass. 
Table 2. Stiffness and damping coefficients for the foot-ground interface and wobbling masses

\begin{tabular}{|c|c|c|c|c|}
\hline & \multicolumn{3}{|c|}{ coefficient $\times 10^{-3}$} & \\
\hline $\begin{array}{c}\text { spring } \\
\text { parameter }\end{array}$ & $\begin{array}{c}\text { height } \\
\text { jump }\end{array}$ & $\begin{array}{c}\text { distance } \\
\text { jump }\end{array}$ & $\begin{array}{c}\text { combined } \\
\text { jumps }\end{array}$ & units \\
\hline $\mathrm{k}_{\mathrm{xt}} \& \mathrm{k}_{\mathrm{xh}}$ & $4798 \times 10^{3}$ & $397 \times 10^{3}$ & $340 \times 10^{3}$ & $\mathrm{Nm}^{-4}$ \\
\hline $\mathrm{k}_{\mathrm{yt}}$ & 2736.7 & 2048.7 & 2070.6 & $\mathrm{Nm}^{-2}$ \\
\hline $\mathrm{k}_{\mathrm{yh}}$ & 160.7 & 160.7 & 160.7 & $\mathrm{Nm}^{-2}$ \\
\hline $\mathrm{b}_{\mathrm{xt}} \& \mathrm{~b}_{\mathrm{xh}}$ & $980 \times 10^{3}$ & $2081 \times 10^{3}$ & $1462 \times 10^{3}$ & $\mathrm{Nsm}^{-4}$ \\
\hline $\mathrm{b}_{\mathrm{yt}}$ & 72.1 & 48.6 & 51.4 & $\mathrm{Nsm}^{-2}$ \\
\hline $\mathrm{b}_{\mathrm{yh}}$ & 119.4 & 196.0 & 134.6 & $\mathrm{Nsm}^{-2}$ \\
\hline $\mathrm{c}_{\mathrm{xt}} \& \mathrm{c}_{\mathrm{xh}}$ & 0.242 & 0.567 & 0.571 & $\mathrm{~m}^{-1}$ \\
\hline \hline $\mathrm{k}_{\mathrm{ca}}$ & 56.2 & 241.5 & 311.9 & $\mathrm{Nm}^{-2}$ \\
\hline $\mathrm{k}_{\mathrm{th}}$ & 123.6 & 386.9 & 384.1 & $\mathrm{Nm}^{-2}$ \\
\hline $\mathrm{k}_{\mathrm{tr}}$ & 179.2 & 356.6 & 306.3 & $\mathrm{Nm}^{-2}$ \\
\hline $\mathrm{b}_{\mathrm{tra}}$ & 1.6 & 0.07 & 0.9 & $\mathrm{Nsm}^{-2}$ \\
\hline $\mathrm{b}_{\mathrm{th}}$ & 4.3 & 0.8 & 6.2 & $\mathrm{Nsm}^{-2}$ \\
\hline 1.3 & 0.08 & 0.6 & $\mathrm{Nsm}^{-2}$ \\
\hline
\end{tabular}

where: $\mathrm{k}=$ stiffness, $\mathrm{b}=$ damping, $\mathrm{x}=$ horizontal, $\mathrm{y}=$ vertical, $\mathrm{t}=$ toe, $\mathrm{h}=$ heel, $\mathrm{ca}=$ calf, th $=$ thigh, $\operatorname{tr}=$ trunk (see equations $(1)-(4)$ ). 
Good agreement was found between the actual performances of running jumps for height and distance and the matching simulations when the parameters from individual trials were used. Objective function scores of $5.6 \%$ and $9.4 \%$ were obtained for the jumps for height and distance respectively (Table 3 ). These scores comprised differences of $3^{\circ}$ and $6^{\circ}$ in the orientation angle at takeoff, $1^{\circ}$ and $2^{\circ}$ in the joint angle configuration at takeoff, $0.4 \%$ and $1.0 \%$ in the angular momentum at takeoff, $2 \%$ and $5 \%$ in the linear momentum at takeoff and RMS differences of $13 \%$ and $22 \%$ in the horizontal and vertical ground reaction forces throughout the simulation. Although the percentage RMS differences for the ground reaction forces were higher than for other variables, the force profiles for simulation and performance were similar (Figure 2). The differences at takeoff between a simulation and a trial produced only small differences in the flight phase (Figures 3 and 4).

Table 3. The effect of using individual and combined parameter sets on the matching simulation scores

\begin{tabular}{|c|c|c|c|c|}
\hline & \multicolumn{2}{|c|}{ jump for height } & \multicolumn{2}{c|}{ jump for distance } \\
\hline component & individual & combined & individual & combined \\
\hline$(1)$ & $3.0^{\circ}$ & $4.9^{\circ}$ & $6.1^{\circ}$ & $6.4^{\circ}$ \\
\hline$(2)$ & $0.8^{\circ}$ & $0.8^{\circ}$ & $1.7^{\circ}$ & $1.7^{\circ}$ \\
\hline$(3)$ & $0.1 \%$ & $0.0 \%$ & $0.0 \%$ & $0.3 \%$ \\
\hline$(4)$ & $1.6 \%$ & $2.8 \%$ & $4.8 \%$ & $4.7 \%$ \\
\hline$(5)$ & $0.4 \%$ & $0.7 \%$ & $1.0 \%$ & $1.3 \%$ \\
\hline$(6)$ & $13.2 \%$ & $14.9 \%$ & $21.7 \%$ & $22.8 \%$ \\
\hline $\begin{array}{c}\text { overall } \\
\text { score }\end{array}$ & $5.6 \%$ & $6.5 \%$ & $9.4 \%$ & $9.9 \%$ \\
\hline
\end{tabular}

where component (1): body orientation at takeoff, component (2): joint angles at takeoff, component (3): time of contact, component (4): horizontal and vertical linear momentum at takeoff, componen (5): angular momentum at takeoff, component (6): horizontal and vertical ground reaction forces throughout the takeoff phase. 

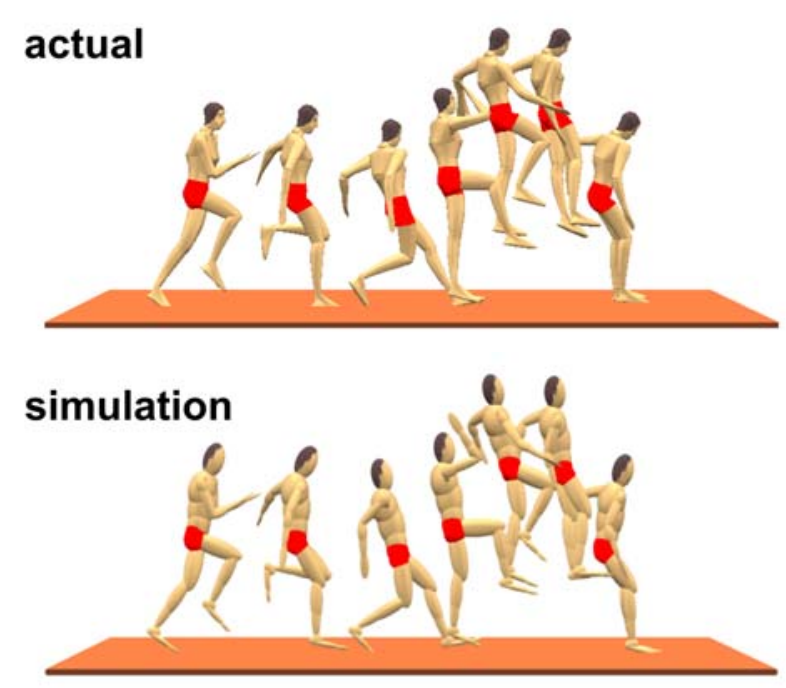

Figure 2. Comparison of vertical ground reaction force in the actual and simulated performances in the jump for height.

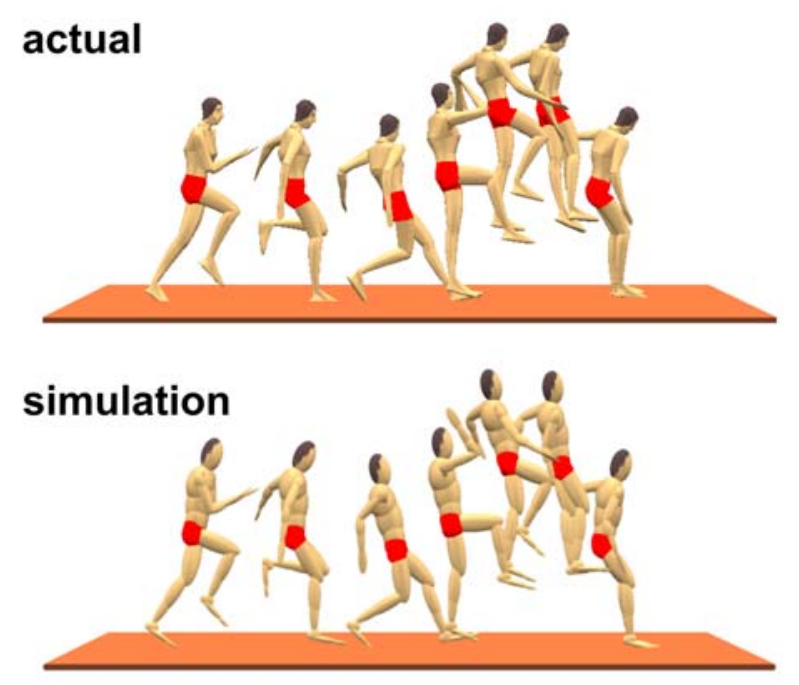

Figure 3. Comparison of actual performance with matching simulation in the jump for height.

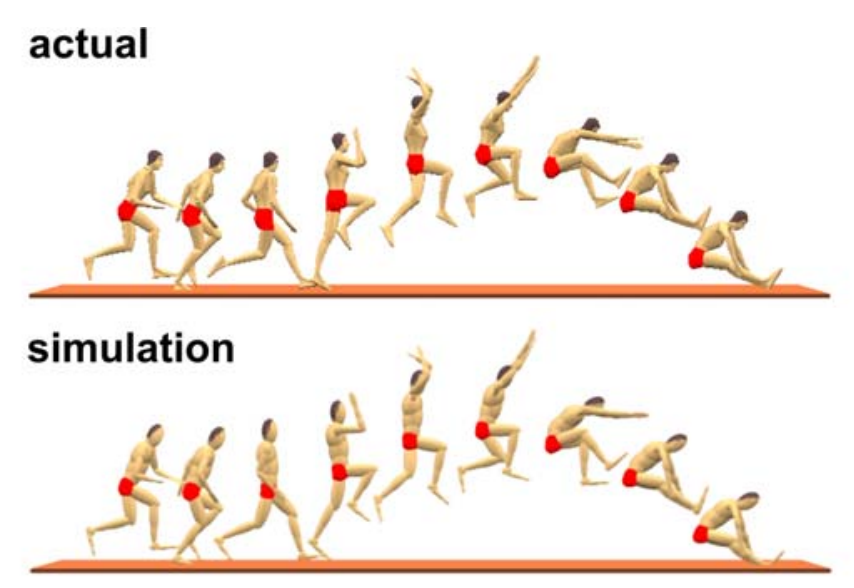

Figure 4. Comparison of actual performance with matching simulation in the jump for distance. 
Using a combined score from the jumps for height and distance to give a common set of visco-elastic parameters resulted in a score of $8.2 \%$ made up $6.5 \%$ for the jump for height and $9.9 \%$ for the jump for distance (less than $1 \%$ increase compared with the individual scores, Table 3). This corresponded to an underestimate of $0.04 \mathrm{~m}$ in the peak height reached by the mass centre during the flight phase in the jump for height and an underestimate of $0.08 \mathrm{~m}$ in the horizontal distance travelled by the mass centre during the flight phase in the jump for distance.

When the parameters determined using a jump for distance were used as input into a simulation for the jump for height the difference between simulation and performance was $44 \%$. When the parameters determined using the jump for height were input into a simulation of the jump for distance the difference between simulation and performance was $30 \%$. This corresponded to an underestimation of $0.48 \mathrm{~m}$ in the peak height reached by the mass centre during the flight phase in the jump for height and an underestimation of $0.10 \mathrm{~m}$ in the distance travelled by the mass centre during the flight phase in the jump for distance.

When the 13 parameters were varied by $\pm 10 \%$ from the common set values the simulation scores increased by $0.1-0.6 \%$ (Table 4 ). The peak forces corresponding to each stiffness and damping parameter are expressed as a percentage of the peak force reached by that visco-elastic element in Table 5. Removing each of the 17 additional kinematic parameters in turn resulted in combined scores which were between $0.4 \%$ and $7.0 \%$ higher than the combined matching scores. When all 17 additional kinematic parameters were removed the optimised combined score rose from $8.2 \%$ to $16.4 \%$. 
Table 4. Mean matching scores in \% corresponding to a $\pm 10 \%$ change in each of the 13 parameters

\begin{tabular}{|c|c|c|}
\hline $\begin{array}{c}\text { spring } \\
\text { parameter }\end{array}$ & $\begin{array}{c}\text { height } \\
\text { jump }\end{array}$ & $\begin{array}{c}\text { distance } \\
\text { jump }\end{array}$ \\
\hline optimum & 6.5 & 9.9 \\
\hline $\mathrm{k}_{\mathrm{xt}} \& \mathrm{k}_{\mathrm{xh}}$ & 7.0 & 10.2 \\
\hline $\mathrm{k}_{\mathrm{yt}}$ & 6.8 & 10.0 \\
\hline $\mathrm{k}_{\mathrm{yh}}$ & 7.1 & 9.9 \\
\hline $\mathrm{b}_{\mathrm{xt}} \& \mathrm{~b}_{\mathrm{xh}}$ & 6.9 & 9.9 \\
\hline $\mathrm{b}_{\mathrm{yt}}$ & 6.7 & 9.9 \\
\hline $\mathrm{b}_{\mathrm{yh}}$ & 6.7 & 10.0 \\
\hline $\mathrm{c}_{\mathrm{xt}} \& \mathrm{c}_{\mathrm{xh}}$ & 6.9 & 10.0 \\
\hline \hline $\mathrm{k}_{\mathrm{ca}}$ & 7.1 & 9.9 \\
\hline $\mathrm{k}_{\mathrm{th}}$ & 6.6 & 10.0 \\
\hline $\mathrm{k}_{\mathrm{tr}}$ & 7.1 & 10.4 \\
\hline $\mathrm{b}_{\mathrm{ca}}$ & 7.1 & 9.9 \\
\hline $\mathrm{b}_{\mathrm{th}}$ & 7.1 & 9.9 \\
\hline $\mathrm{b}_{\mathrm{tr}}$ & 7.1 & 9.9 \\
\hline
\end{tabular}

where: $\mathrm{k}=$ stiffness, $\mathrm{b}=$ damping, $\mathrm{x}=$ horizontal, $\mathrm{y}=$ vertical, $\mathrm{t}=\mathrm{toe}, \mathrm{h}$ $=$ heel, $\mathrm{ca}=$ calf, th $=$ thigh, $\operatorname{tr}=$ trunk (see equations $(1)-(4)$ ). 
Table 5. Peak forces for stiffness and damping as a percentage of overall peak force for each visco-elastic element

\begin{tabular}{|c|c|c|}
\hline spring parameter & $\begin{array}{c}\text { height } \\
\text { jump }\end{array}$ & $\begin{array}{c}\text { distance } \\
\text { jump }\end{array}$ \\
\hline horizontal stiffness (foot) & 59 & 45 \\
\hline horizontal damping (foot) & 85 & 86 \\
\hline vertical stiffness (toe) & 98 & 72 \\
\hline vertical damping (toe) & 39 & 43 \\
\hline vertical stiffness (heel) & 38 & 25 \\
\hline vertical damping (heel) & 98 & 97 \\
\hline \hline shank stiffness & 99 & 95 \\
\hline shank damping & 40 & 54 \\
\hline thigh stiffness & 82 & 81 \\
\hline thigh damping & 43 & 44 \\
\hline trunk stiffness & 100 & 100 \\
\hline trunk damping & 3 & 4 \\
\hline tal
\end{tabular}

Note: Equations (1) - (4) express the force in a visco-elastic element as the sum of a stiffness component and a damping component

\section{Discussion}

Computer simulation models are often used to investigate the mechanics of sports movements. One vital element in this process is the determination of subject-specific model parameter values as this allows the simulation model to be evaluated quantitatively by comparing simulations with actual performances. This paper has described a method of determining subject-specific visco-elastic parameters using an angle-driven simulation model with the intention of using these parameter values subsequently in a torque-driven simulation model in order to investigate optimum jumping technique.

Limitations of the method include the use of kinematic data to drive the model through a dynamic movement involving an impact together with assumptions made in developing the model. The simulation model was designed to include the important features of running jumps without being so complex as to prevent realistic subject-specific parameters to be determined. Allowing for out of plane motion at the hips and including a more complex representation of the foot might have improved the structure of the model but this would have made parameter determination more difficult. Driving the model using joint angle time histories constrains the simulated movement, as do any errors in the data - which may result in unrealistic joint torques. As a consequence the matching of the simulation with the actual performance may be less good than for a torque-driven forwards dynamics model. The advantage of specifying joint angles is that there are fewer parameters to be determined and this outweighs the negative effect of errors in the kinematic data. The matching simulations were found to be sensitive to the additional kinematic parameters, demonstrating the need for their inclusion in the optimisation process and the need to determine accurate kinematic data during impacts. In future the use of a high speed marker-based motion analysis system may improve the quality of the kinematic data so long as an appropriate procedure for joint centre 
location is used. Despite the limitations, it appears that the method of determining viscoelastic parameters gives usable estimates of the elastic parameters as the matching simulations compare well with the actual performances.

The peak force contributions from stiffness and damping components for the wobbling mass segments (equations (1) and (2)) were similar for the shank and thigh segments but different from the trunk (Table 5). This is reasonable as the shank and thigh are similar in structure while the trunk comprises internal organs as well as muscle. Although no movement data on the wobbling masses were used in the optimisation score, the force plate data will have influenced the parameter values obtained. The visco-elastic parameters for the vertical foot-ground interface at the toe and heel (equation (3)) resulted in differing contributions to the total vertical force with a high damping contribution at the heel and a high stiffness contribution at the toe (Table 5). A good estimate of the vertical damping parameter at the heel may be expected since only the heel was in contact during the first part of the foot contact phase and a high damping force was required to slow the velocity of the heel and match the total vertical force. Similarly a good estimate of the vertical stiffness parameter at the toe may be expected since during the second half of the foot contact phase when the foot is moving slowly the contribution from stiffness (at the toe) must be high to match the total vertical force. These expectations are supported in general by Table 2 in which these parameter values from the two individual jumps are similar to the combined parameter values. The other parameters (stiffness at the heel and damping at the toe) have much smaller relative contributions and although there is less confidence in these parameter values, the forces are low and therefore they have a small influence on performance. Similar considerations apply to the horizontal foot parameters which were not separated into heel and toe contributions: the damping parameter being determined by the impact data soon after touchdown and the stiffness parameter being determined in the later phase of contact.

The maximum vertical depression at the heel in the simulated jumps was $30 \mathrm{~mm}$ which is comparable with the sum of barefoot heel pad deformation of $7 \mathrm{~mm}$ (Pain and Challis, 2001) and training shoe deformation of $15 \mathrm{~mm}$ (Alexander and Bennet, 1989) obtained for lighter loading than jumping. The visco-elastic parameter values for the wobbling masses cannot be compared easily with values from the literature since a variety of functions have been used to model visco-elastic forces. The visco-elastic parameters shown in Table 2 generally show a fairly wide range of variation between individual values, indicating that the individual values are not particularly robust. On the other hand the combined stiffness values for the calf, thigh and trunk are of similar magnitude suggesting a measure of robustness. The maximum deformations of the calf and thigh wobbling masses were $33 \mathrm{~mm}$ and $43 \mathrm{~mm}$ respectively which are comparable with mean deformations of $18 \mathrm{~mm}$ and $32 \mathrm{~mm}$ for drop landings onto both heels from a height of $0.4 \mathrm{~m}$ (Pain and Challis, in press).

Reducing the number of visco-elastic parameters to be determined and using two trials for determining the visco-elastic parameters minimised the risk of overfitting the data. Perturbing each of the 13 visco-elastic parameters by $\pm 10 \%$ had a distinct but generally small effect on the matching score (Table 4), indicating that these parameters needed to be included and that the model had not over-fit the data. Furthermore the fact that the match between simulation and performance was still good when a single common set of stiffness and damping parameters was used is encouraging since poor agreement would suggest that some model deficiency was being compensated for by the individual parameter sets.

It is clear that the use of more than one performance in the optimisation procedure is necessary in order to obtain a robust parameter set that may be used generally for similar movements. Whether two trials is sufficient for this purpose is unclear although using trials of different types of jumps should give parameters that are applicable to a wider range of 
jumps than trials from the same type of jump. In the future several trials should be used to generate the parameter set, which should then be evaluated using an independent trial.

\section{References}

Alexander, R.M., Bennett, M., 1989. How elastic is a running shoe? New Scientist, 15 July, 45-46.

van den Bogert, A.J., Nigg, B.M., 1999. Simulation. In: Nigg, B. M. and Herzog, W. (Eds.), Biomechanics of the musculo-skeletal system. Chichester: John Wiley \& Sons Ltd, pp.551-566.

Clarys, J.P., Marfell-Jones, M.J., 1986. Anthropometric prediction of component tissue masses in the minor limb segments of the human body. Human Biology 58, 761-769.

Corana, A., Marchesi, M., Martini, C., Ridella, S., 1987. Minimising multimodal functions of continuous variables with the "simulated annealing" algorithm. ACM Transactions on Mathematical Software 13, 262-280.

Dempster, W.T., 1955. Space requirements of the seated operator, Wright-Paterson Air Force Base, Ohio WADC-TR: 55-159.

Denoth, J., Gruber, K., Ruder, H., Keppler, M., 1985. Forces and torques during sport activities with high accelerations. In Perren, S.M. and Schneider, E. (Eds.), Biomechanics: Current interdisciplinary research). Mertinus Nijhoff Publishers, Dordrect, pp. 663-668.

Gilchrist, L.A., Winter, D.A., 1996. A two-part, viscoelastic foot model for use in gait simulations. Journal of Biomechanics 29, 795-798.

Gruber, K., Ruder, H., Denoth, J., Schneider, K., 1998. A comparative study of impact dynamics: wobbling mass model versus rigid body models. Journal of Biomechanics 31, 439-444.

Hatze, H., 1980. A Mathematical model for the computational determination of parameter values of anthropomorphic segments. Journal of Biomechanics 13, 833-843.

Hatze, 1981. A comprehensive model for human motion simulation and its application to the take-off phase of the long jump. Journal of Biomechanics 14, 135-142.

Hubbard, M., Hibbard, R.L., Yeadon, M.R., Komor, A., 1989. A multisegment dynamic model of ski jumping. International Journal of Sport Biomechanics 5, 258-274.

Jensen, R.K., 1978. Estimation of the biomechanical properties of three body types using a photogrammetric method. Journal of Biomechanics 11, 349-358.

Kane, T.R., Levinson, D.A., 1996. Dynamics online: Theory and implementations with AUTOLEV. Online Dynamics Inc, Sunnyvale.

Karara, H.M., 1980. Non-metric cameras. In Aktinson, K. B. (Ed.), Developments in close range photogrammetry -1 . Applied Science Publishers, London, pp. 63-80.

King, M.A., Yeadon, M.R., 2002. Determining subject-specific torque parameters for use in a torque-driven simulation model of dynamic jumping. Journal of Applied Biomechanics 18, 207-217.

Neptune, R.R., Hull, M.L., 1999. A theoretical analysis of preferred pedaling rate selection in endurance cycling. Journal of Biomechanics 32, 409-415.

Neptune, R.R., Wright, I.C., van den Bogert, A.J., 2000. A method for numerical simulation of single limb ground contact events: Application to heel-toe running. Computer Methods in Biomechanics and Biomedical Engineering 3, 321-324.

Nigg, B.M., Cole, G.K., Bruggeman, G.P., 1995. Impact forces during heel toe running. Journal of Applied Biomechanics 11, 407-432.

Pain, M.T.G., Challis, J.H., 2001. The role of the heel pad and shank soft tissue during impacts: a further resolution of a paradox. Journal of Biomechanics 34, 327-333. 
Pain, M.T.G., Challis, J.H., in press. The influence of soft tissue movement on ground reaction forces, joint torques and joint reaction forces in drop landings. Journal of Biomechanics.

van Soest, A.J., Schwab, A.L., Bobbert, M.F., van Ingen Schenau, G.J., 1993. The influence of the biarticularity of the gastrocnemius muscle on vertical-jumping achievement. Journal of Biomechanics 26, 1-8.

Wood, G.A., Jennings, L.S., 1979. On the use of spline functions for data smoothing. Journal of Biomechanics 12, 447-479.

Yeadon, M.R., 1990a. The simulation of aerial movement - I. The determination of orientation angles from film data. Journal of Biomechanics 23, 59-66.

Yeadon, M.R., 1990b. The simulation of aerial movement - II. A mathematical inertia model of the human body. Journal of Biomechanics 23, 67-74.

Yeadon, M.R., 1990c. The simulation of aerial movement - III. The determination of the angular momentum of the human body. Journal of Biomechanics 23, 75-83.

Yeadon, M.R., Atha, J., Hales, F.D., 1990. The simulation of aerial movement - IV. A computer simulation model. Journal of Biomechanics 23, 85-89.

Yeadon, M.R., Challis J.H., 1994. The future of performance-related sports biomechanics research. Journal of Sports Sciences 12, 3-32.

Yeadon, M.R., King, M.A., 1999. A method for synchronising digitised video data. Journal of Biomechanics 32, 983-986.

Yeadon, M.R., King, M.A., 2002. Evaluation of a torque driven simulation model of tumbling. Journal of Applied Biomechanics 18, 195-206. 